Provided for non-commercial research and education use. Not for reproduction, distribution or commercial use.

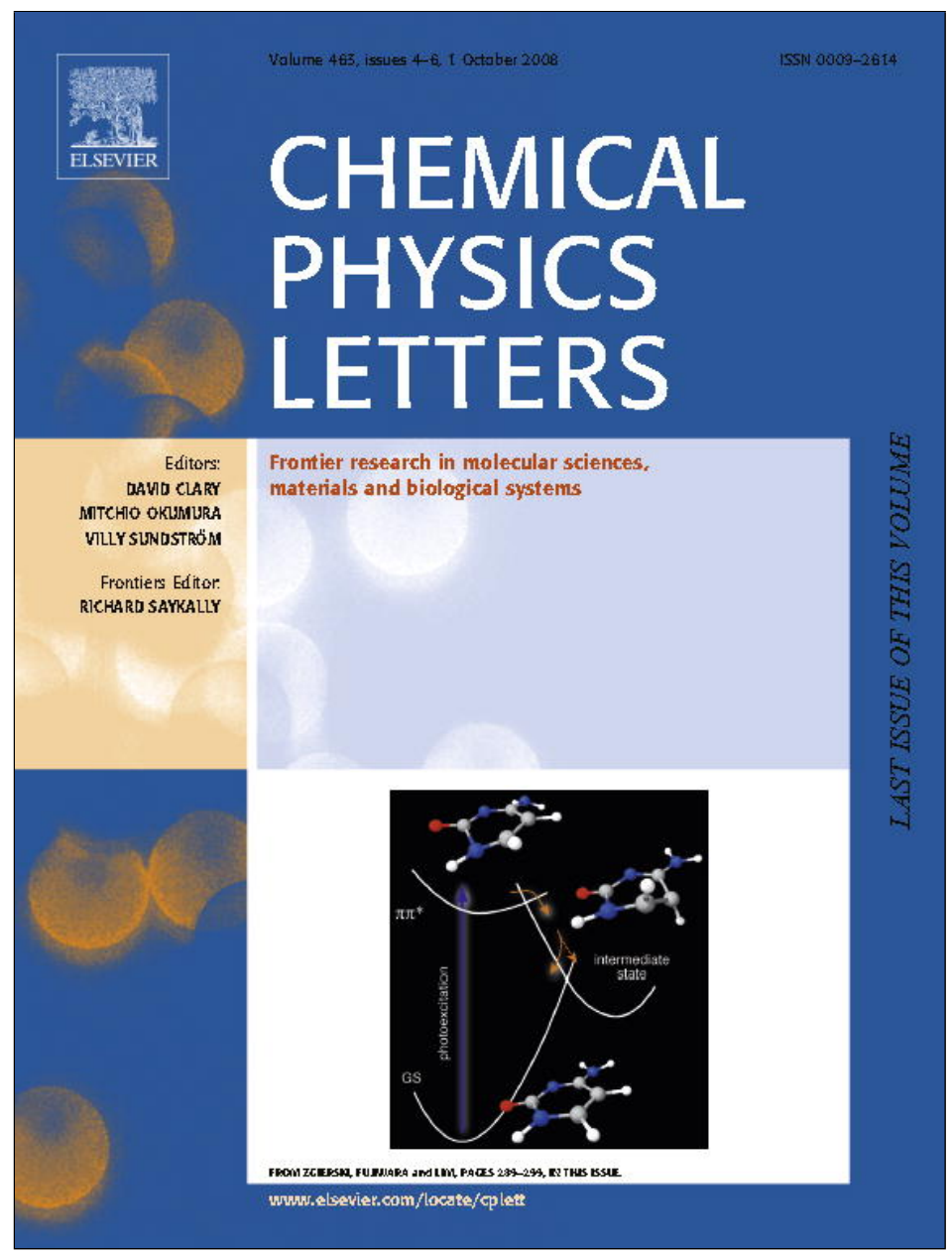

This article appeared in a journal published by Elsevier. The attached copy is furnished to the author for internal non-commercial research and education use, including for instruction at the authors institution and sharing with colleagues.

Other uses, including reproduction and distribution, or selling or licensing copies, or posting to personal, institutional or third party websites are prohibited.

In most cases authors are permitted to post their version of the article (e.g. in Word or Tex form) to their personal website or institutional repository. Authors requiring further information regarding Elsevier's archiving and manuscript policies are encouraged to visit:

http://www.elsevier.com/copyright 


\title{
New features in the dynamics of a ferroin-catalyzed Belousov-Zhabotinsky reaction induced by a zwitterionic surfactant
}

\author{
Federico Rossi, Rosario Varsalona, Maria Liria Turco Liveri * \\ Dipartimento di Chimica Fisica, Università degli Studi di Palermo, Viale delle Scienze Ed. 17, 90128 Palermo, Italy
}

\section{A R T I C L E I N F O}

\section{Article history:}

Received 2 July 2008

In final form 21 August 2008

Available online 27 August 2008

\begin{abstract}
A B S T R A C T
Interactions between reaction-diffusion systems and aggregated host environments are a subject of widespread interest. In this work, the behavior of the Belousov-Zhabotinsky reaction was investigated in a micellar environment formed by the zwitterionic surfactant $N$-tetradecyl- $N, N$-dimethylamine oxide $\left(\mathrm{C}_{14} \mathrm{DMAO}\right)$. The appearance of an induction period with a threshold-like dependence upon the surfactant concentration, was detected at $\left[\mathrm{C}_{14} \mathrm{DMAO}\right]=5.0 \times 10^{-3} \mathrm{~mol} \mathrm{dm}{ }^{-3}$. These new features were explained in terms of the segregation ability typical of the amphiphilic self-assembling systems. Numerical simulations were also performed to confirm the proposed mechanism.
\end{abstract}

(C) 2008 Elsevier B.V. All rights reserved.

\section{Introduction}

The Belousov-Zhabotinsky (BZ) reaction, initially proposed as a simplified scheme of a metabolic pathway (Krebs cycle) [1], was subsequently adopted as a more general model for certain major nonlinear phenomena, e.g. enzymatic catalysis, biological oscillations and pattern formation [2-4]. The BZ reaction, in its most used recipe, consists in the catalytic oxidation of malonic acid (MA), by bromate ions in a strongly acidic aqueous solution [5]. Metal redox couples such as $\mathrm{Ce}(\mathrm{IV}) / \mathrm{Ce}(\mathrm{III})$ or ferriin/ferroin $\left(\mathrm{Fe}(\text { phen })_{3}^{3+} /\right.$ $\mathrm{Fe}(\mathrm{phen})_{3}^{2+}$ ), are often used as catalysts.

Several authors [5-7] pointed out the different behavior between cerium and ferroin-catalyzed BZ systems, in particular the absence of a pre-oscillatory induction period (IP) for the latter (even if under certain experimental conditions, IP appears also for ferroin systems [8-10]), and a different dependence of the oscillation frequency upon the relative initial concentrations of reactants. The pre-oscillatory induction period is the typical single length oscillation at the start of the cerium-catalyzed $\mathrm{BZ}$ system [5]. During the IP, the $\mathrm{Br}^{-}$concentration is increased and brominated organic species are accumulated. According to the GTF model [11] the length of IP is determined by the concentration of bromomalonic acid (BrMA). The crucial amount of BrMA necessary for the onset of oscillations is produced through two main pathways: (a) the bromination of the enol form of malonic acid by $\mathrm{Br}_{2}$ and (b) the reaction between $\mathrm{Br}_{2}$ and the malonyl radical formed in the Ce-MA subsystem [12].

The oxidation potential of the redox couple ferriin/ferroin is significantly lower than the couple $\mathrm{Ce}(\mathrm{IV}) / \mathrm{Ce}(\mathrm{III})$ and this is the main reason accounting for the differences in the two oscillating sys-

\footnotetext{
* Corresponding author. Fax: +39 091590015

E-mail address: tliveri@unipa.it (M.L.T. Liveri).
}

tems. Various hypothesis have been proposed to explain the reactivity of the ferroin toward the organic substrates, in particular it was postulated that ferroin could react only with bromomalonic acid. Recently, Noszticzius and coworkers [13] unambiguously proved that ferriin does not react with malonic acid, thus preventing the bromide formation through the aforementioned reaction pathway (b). Due to the low redox potential of the catalyst couple, the reaction of ferroin with the oxybromine species has been identified as an alternative $\mathrm{Br}^{-}$source [5,14], according to the following reaction scheme:

$$
\begin{aligned}
& 2 \mathrm{Fe}(\text { phen })_{3}^{2+}+\mathrm{BrO}_{3}^{-}+3 \mathrm{H}^{+} \rightarrow 2 \mathrm{Fe}(\text { phen })_{3}^{3+}+\mathrm{HBrO}_{2}+\mathrm{H}_{2} \mathrm{O} \\
& 2 \mathrm{Fe}(\text { phen })_{3}^{2+}+\mathrm{HBrO}_{2}+2 \mathrm{H}^{+} \rightarrow 2 \mathrm{Fe}(\text { phen })_{3}^{3+}+\mathrm{HOBr}+\mathrm{H}_{2} \mathrm{O} \\
& 2 \mathrm{Fe}(\text { phen })_{3}^{2+}+\mathrm{HOBr}+\mathrm{H}^{+} \rightarrow 2 \mathrm{Fe}(\text { phen })_{3}^{3+}+\mathrm{Br}^{-}+\mathrm{H}_{2} \mathrm{O} \\
& 2 \mathrm{Fe}(\text { phen })_{3}^{2+}+\mathrm{Br}_{2} \rightarrow 2 \mathrm{Fe}(\text { phen })_{3}^{3+}+2 \mathrm{Br}^{-}
\end{aligned}
$$

The combination of a chemical oscillator with confined reaction environments is a subject extensively studied during the past years. Among the others, surfactant forming micelles (direct and reverse) revealed to be very fascinating and promising [15-23]. The so-called direct micelles are formed by the spontaneous clustering of amphiphilic molecules to give aggregates where the hydrophobic moieties are segregated from the outer hydrophilic environment. One of the most important properties of micellar solutions is their ability to selectively interact with the reacting substrates present in the medium, depending on their chemical proprieties (e.g. charge and/or hydrophobicity) [24,25].

Following our previous works $[16,17,19,20]$ about chemical oscillators and surfactants, in this Letter we focus on the dynamics of the ferroin-catalyzed BZ system perturbed by using a peculiar and versatile zwitterionic surfactant; namely, $\mathrm{N}$-tetradecyl- $\mathrm{N}, \mathrm{N}$ dimethylamine oxide $\left(\mathrm{C}_{14} \mathrm{DMAO}\right)$, in a stirred batch reactor. $\mathrm{C}_{14} \mathrm{DMAO}$ has been classified between the cationic and purely 
nonionic surfactants [26], and, like others $n$-alkyldimethylaminoxides, it has the capability to form large rod-like micelles with lengths of several thousand Angströms in the presence of electrolytes $[26,27]$.

\section{Experimental}

Malonic acid, sodium bromate, sodium bromide, sulfuric acid and ferroin $\left(\mathrm{Fe}(\mathrm{o} \text {-phen })_{3} \mathrm{SO}_{4}\right)$ were commercial grade reactants (Fluka), $\mathrm{C}_{14} \mathrm{DMAO}$ (chemical structure shown in Fig. 1) was a gift of Prof. H. Hoffmann (Bayreuth Center for Colloids \& Interfaces). All chemicals were used without further purification. Stock solutions were prepared by weight before use. Deionized water from reverse osmosis (Elga, model Option 3), having a resistivity higher than $1 \mathrm{M} \Omega \mathrm{cm}$, was used to prepare all solutions.

Samples for the kinetics runs were prepared in spectrophotometric quartz cuvettes $(1 \times 1 \times 5 \mathrm{~cm})$ diluting and gently stirring a solution containing the $\mathrm{BZ}$ components, except ferroin, with different amount of $C_{14}$ DMAO stock solution $\left(0.20 \mathrm{~mol} \mathrm{dm}^{-3}\right)$. Oscillations were started by adding ferroin. Finally, cuvettes were placed in a UV-Vis spectrophotometer (Beckman DU-640, equipped with thermostatted compartments and a magnetic stirring apparatus) for data acquisition. The initial concentrations of the $\mathrm{BZ}$ reactants in the mixture were: $[\mathrm{MA}]=0.03 \mathrm{~mol} \mathrm{dm}^{-3},\left[\mathrm{NaBrO}_{3}\right]=0.12$ mol dm${ }^{-3}$, [ferroin] $=5.0 \times 10^{-4} \mathrm{~mol} \mathrm{dm}^{-3},\left[\mathrm{H}_{2} \mathrm{SO}_{4}\right]=0.30 \mathrm{~mol} \mathrm{dm}^{-3}$ and $\left[C_{14} \mathrm{DMAO}\right]$ was varied in the range $0-9.0 \times 10^{-3} \mathrm{~mol} \mathrm{dm}^{-3}$. Time series were recorded following the absorbance of ferroin at a wavelength $\lambda=510 \mathrm{~nm}$ where the ferroin molar extinction coefficient $\epsilon=1.1 \times 10^{4} \mathrm{~mol}^{-1} \mathrm{dm}^{3} \mathrm{~cm}^{-1}$.

The critical micelle concentration (c.m.c.) of $\mathrm{C}_{14} \mathrm{DMAO}$ in aqueous solutions was estimated as the intersection point of the two linear plots, above and below the c.m.c., of the surface tension versus log of surfactant concentration.

Surface tension values were determined both in the absence and in the presence of BZ reactants at the concentrations used for experiments. Measurements were carried out by means of a KSV-Sigma 70 automatic tensiometer by using the Whilelmy plate method. The c.m.c. value in the presence of BZ reactants was $6.3 \times 10^{-5} \mathrm{~mol} \mathrm{dm}^{-3}$. The lower value with respect to that in water $\left(1.6 \times 10^{-4} \mathrm{~mol} \mathrm{dm}^{-3}\right.$, which is in complete agreement with that reported in the literature [26]) is in line with the effect caused by the presence of added electrolytes.

All measurements were performed under constant stirring at $20.0 \pm 0.1^{\circ} \mathrm{C}$.

The oscillation period $\tau$, has been evaluated as the temporal difference between successive peaks from the time series recorded spectrophotometrically. In particular, we refer to $\tau_{\mathrm{m}}$ which represents the mean period of the first 6 min of oscillations. All oscillation parameters with relative errors were calculated from five different experimental runs.

\section{Results and discussion}

The influence of $\mathrm{C}_{14} \mathrm{DMAO}$ on the dynamics of the ferroin-catalyzed $B Z$ reaction was investigated over a wide surfactant concentration range. The analysis of the experimental timeseries showed that in the surfactant concentration range $0<\left[\mathrm{C}_{14} \mathrm{DMAO}\right]<5.0 \times 10^{-3}$

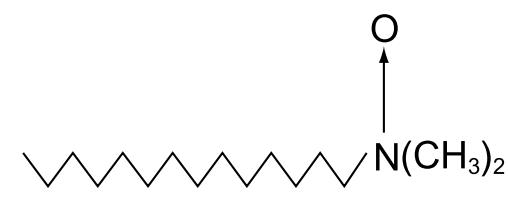

Fig. 1. Chemical structure of $C_{14}$ DMAO.

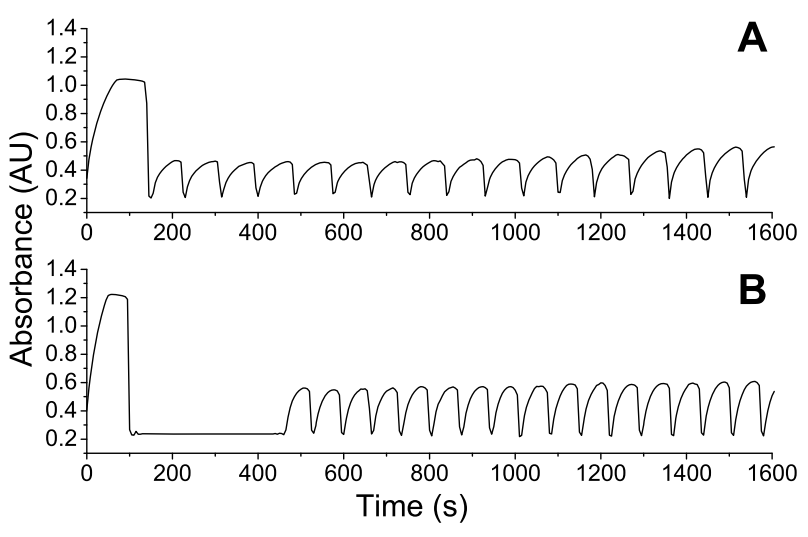

Fig. 2. Comparison between a $B Z$ reaction in the absence $(A)$ and in the presence of $\left[C_{14} \mathrm{DMAO}\right]_{\mathrm{cr}}=6.0 \times 10^{-3} \mathrm{~mol} \mathrm{dm}{ }^{-3}(\mathrm{~B})$ at $20.0^{\circ} \mathrm{C}$. For both systems the following initial reactants concentrations were used: $[\mathrm{MA}]=0.03 \mathrm{~mol} \mathrm{dm}^{-3},\left[\mathrm{NaBrO}_{3}\right]=$ $0.12 \mathrm{~mol} \mathrm{dm}^{-3}$, [ferroin] $=5.0 \times 10^{-4} \mathrm{~mol} \mathrm{dm}^{-3}, \quad\left[\mathrm{H}_{2} \mathrm{SO}_{4}\right]=0.30 \mathrm{~mol} \mathrm{dm}^{-3}$. The absorbance of ferroin was measured at $\lambda=510 \mathrm{~nm}$.

mol dm${ }^{-3}$, both the qualitative and the quantitative profiles of the absorbance as a function of time, were substantially unchanged with respect to that in the absence of surfactant. When a critical concentration of $\left[C_{14} \text { DMAO }\right]_{\mathrm{cr}}=5.0 \times 10^{-3} \mathrm{~mol} \mathrm{dm}^{-3}$ was reached a new feature in the dynamics appeared, namely an induction period before the oscillating regime (Fig. 2).

As mentioned in Section 1, the presence of the pre-oscillatory stage in a ferroin-catalyzed BZ system is quite surprising. In previous experiments with an anionic surfactant (sodium dodecyl sulphate, SDS) [20], we did not observe similar effects; conversely we found that negatively charged micelles induced an acceleration of the oscillatory dynamics. Paul [18] found that an IP appeared when BZ was conducted in positively charged micelles (cetyltrimethylammonium bromide, CTAB), while the dynamics were completely changed in the presence of nonionic or zwitterionic surfactants.

The dependence of the IP length upon the surfactant concentration is depicted in Fig. 3. Since the IP shows a threshold-like dependence on the surfactant concentration, [ $\left.\mathrm{C}_{14} \mathrm{DMAO}\right]$ could be considered a bifurcation parameter for the reaction dynamics. This fact suggests a strong interaction between the surfactant and one or more of the chemical species crucial for the temporal evolution of the $\mathrm{BZ}$ reaction.

Beyond the critical value $\left[\mathrm{C}_{14} \mathrm{DMAO}\right]_{\mathrm{cr}}$, the length of the induction period was found to vary with $\left[\mathrm{C}_{14} \mathrm{DMAO}\right]$. In particular, after

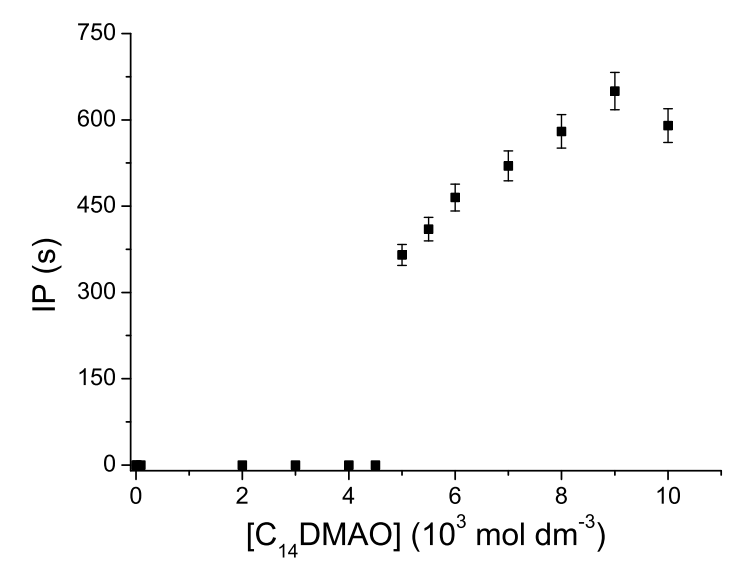

Fig. 3. Dependence of the IP upon the concentration of $C_{14}$ DMAO. At $\left[\mathrm{C}_{14} \mathrm{DMAO}\right]_{\mathrm{cr}}=5.0 \times 10^{-3} \mathrm{~mol} \mathrm{dm}^{-3}$ the system undergoes a bifurcation and an induction period appears. 
A
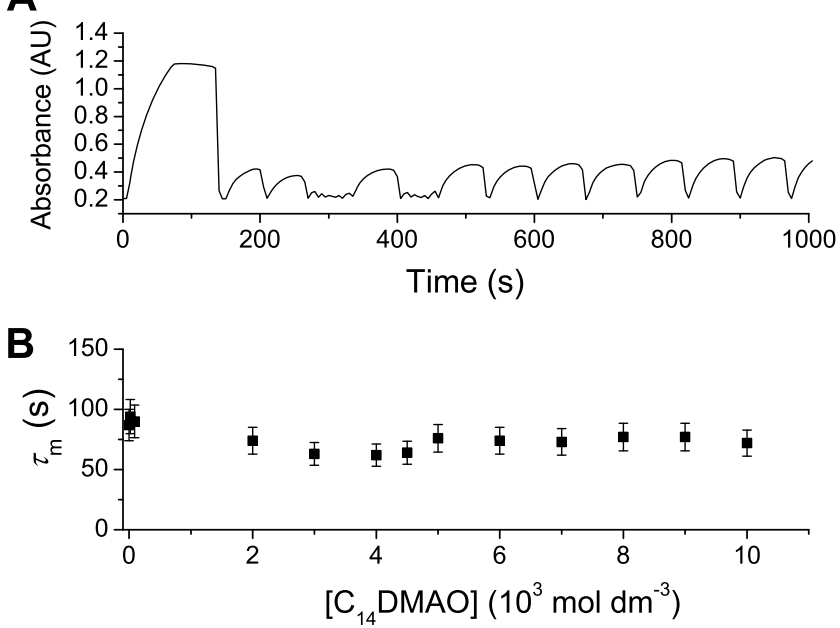

Fig. 4. (A) Dynamics of the $B Z$ reaction in the presence of $\left[\mathrm{C}_{14} \mathrm{DMAO}\right]_{\mathrm{cr}}=4.8 \times 10^{-3} \mathrm{~mol} \mathrm{dm}^{-3}$, (B) dependence of the oscillation period $\tau_{\mathrm{m}}$ upon the concentration of $\mathrm{C}_{14} \mathrm{DMAO}$. The experimental conditions are the same of those reported in Fig. 2.

an increase, it seems that the IP value tends to attain a plateau. Unfortunately, we could not perform experiments above $\left[\mathrm{C}_{14} \mathrm{DMAO}\right]=1.0 \times 10^{-2} \mathrm{~mol} \mathrm{dm}^{-3}$, due to the high viscosity of the solutions.

We also performed several experiments in the narrow interval $4.0 \times 10^{-3}<\left[C_{14} \mathrm{DMAO}\right]<5.0 \times 10^{-3} \mathrm{~mol} \mathrm{dm}^{-3}$. We could not find a clearly defined induction period in this region; the relaxation oscillations during the first 400-500 s were randomly staggered by fast oscillations with very small amplitude or intervals where oscillations were completely damped (Fig. 4A). Fig. 4B shows the dependence of the oscillation period $\tau_{\mathrm{m}}$ upon the surfactant concentration. Perusal of this figure reveals that $\tau_{\mathrm{m}}$ is not as sensitive as the IP to the presence of the micelles in solution, and its behavior does not dramatically change. Actually, $\tau_{\mathrm{m}}$ seems to slightly decrease beyond the c.m.c. ( $\simeq 90 \rightarrow \simeq 75 \mathrm{~s}$ ), but after this value it is no more sensitive to the surfactant concentration increase. In fact, the small variation before and after $\left[\mathrm{C}_{14} \mathrm{DMAO}\right]_{\mathrm{cr}}$ are within the experimental error.

The different behavior manifested by the IP and $\tau_{\mathrm{m}}$, is of crucial help in understanding how the presence of the surfactant influences the BZ reaction dynamics. A sensitivity analysis [28] showed that the most important step in determining the oscillation period of the $\mathrm{BZ}$ reaction is the oxidation of the organic substrate by the catalyst to regenerate bromide (Process C in FKN model [29]). In the ferroin-catalyzed system process $\mathrm{C}$ is

$$
\begin{aligned}
2 \mathrm{Fe}(\text { phen })_{3}^{3+}+\mathrm{BrMA} \rightarrow & f \mathrm{Br}^{-}+2 \mathrm{Fe}(\text { phen })_{3}^{2+} \\
& + \text { other products }
\end{aligned}
$$

The fact that $\tau_{\mathrm{m}}$ is not significantly altered by the presence of the surfactant suggests that the catalyst is not located in the micellar pseudophase, but it is confined in the aqueous one. We confirmed this hypothesis by performing a spectrophotometric analysis of the ferroin decomposition reaction rate:

$\mathrm{Fe}(\text { phen })_{3}^{2+}+3 \mathrm{H}^{+} \rightarrow \mathrm{Fe}(\mathrm{II})+3($ phen $) \mathrm{H}^{+}$

The first order rate constant was found to be $8.3 \pm 0.5 \times 10^{-3} \mathrm{~s}^{-1}$ both in the absence and in the presence of the surfactant at various concentrations. Moreover the peak shape of the ferroin remained unchanged in the micellar medium. These evidences allowed us to rule out any interactions, either electrostatic or hydrophobic, between the ferroin and the aggregated system and suggested that others key species have to play a relevant role.
Bromine is involved in pathway (a) responsible for the induction period (see Section 1); its role in BZ/micelles systems was investigated in our previous works and evidences for the $\mathrm{Br}_{2}$ solubilization in different type of aggregated systems were given ([19] and references therein). For the $\mathrm{BZ} / \mathrm{C}_{14} \mathrm{DMAO}$ system, preliminary experiments showed a strong association between $\mathrm{Br}_{2}$ and the micellized surfactant. This is coherent with the high hydrophobicity of the molecular halogen, which tend to move in the non-polar pseudophase inside the micelles. In fact, from spectrophotometric measurements, it was found that by mixing the molecular bromine with different aqueous zwitterionic solutions, a new absorption band with a maximum at $\lambda=271 \mathrm{~nm}$ appeared. At high concentration of both $\mathrm{Br}_{2}$ and $\mathrm{C}_{14} \mathrm{DMAO}$ the formation of a yellowish adduct was also detected. In order to evaluate the influence of bromine on the IP, we decided to monitor the response of the $B Z / C_{14} D M A O$ system by forming $\mathrm{Br}_{2}$ in situ. This was achieved by adding an increasing amount of $\mathrm{NaBr}$ to different solutions at $\left[\mathrm{C}_{14} \mathrm{DMAO}\right]=$ $5.0 \times 10^{-3} \mathrm{~mol} \mathrm{dm}{ }^{-3}$. The added bromide reacts with $\mathrm{BrO}_{3}^{-}$according to the stoichiometry:

$\mathrm{BrO}_{3}^{-}+5 \mathrm{Br}^{-}+6 \mathrm{H}^{+} \rightarrow 3 \mathrm{Br}_{2}+3 \mathrm{H}_{2} \mathrm{O}$

the $\mathrm{Br}_{2}$ produced in (3), immediately reacts with the enol form of malonic acid to yield BrMA according to the following scheme:

$\mathrm{CH}_{2}(\mathrm{COOH})_{2} \rightleftharpoons(\mathrm{COOH}) \mathrm{CHC}(\mathrm{OH})_{2}$

$(\mathrm{COOH}) \mathrm{CHC}(\mathrm{OH})_{2}+\mathrm{Br}_{2} \rightarrow \mathrm{BrCH}(\mathrm{COOH})_{2}+\mathrm{H}^{+}+\mathrm{Br}^{-}$

during the samples preparation, $\mathrm{NaBr}$ was added to the $\mathrm{BZ}$ mixture before the catalyst; oscillations were then started by adding the ferroin only after that the typical brown-red color of bromine disappeared from the solution.

Fig. 5 shows how the concentration of added bromide, and consequently of $\mathrm{Br}_{2}$ and $\mathrm{BrMA}$, influences the length of the induction period. A confront between Figs. 3 and 5 reveals an almost specular response of the induction period toward the presence of the surfactant and of the bromide, respectively. In fact, increasing the amount of bromide in solution leads to a decrease in the induction period length and eventually to a new bifurcation after which the IP completely disappears.

In order to further test our mechanistic hypothesis, we also simulated the observed behavior of the $\mathrm{BZ} / \mathrm{C}_{14} \mathrm{DMAO}$ system. As mentioned in Section 1, the mechanism of a ferroin-catalyzed BZ reaction is not well understood, and, to the best of our knowledge, models that reproduce quantitatively all the characteristics of the system, have not been yet developed. We performed numerical simulations by combining reactions (B1)-(B4), (E1) and (E2) with

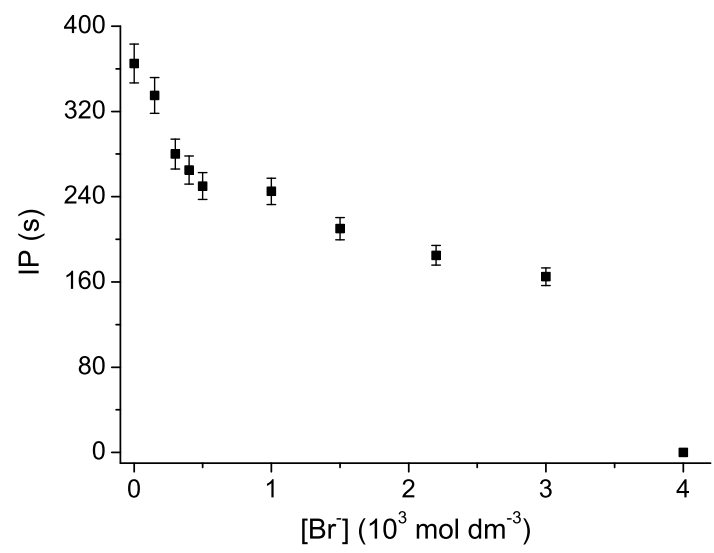

Fig. 5. Dependence of the IP upon the concentration of added $\mathrm{NaBr}$. For all systems the following initial reactants concentrations were used: $[\mathrm{MA}]=0.03 \mathrm{~mol} \mathrm{dm}^{-3}$ $\left[\mathrm{NaBrO}_{3}\right]=0.12 \mathrm{~mol} \mathrm{dm}^{-3}$, [ferroin $]=5 \times 10^{-4} \mathrm{~mol} \mathrm{dm}^{-3},\left[\mathrm{H}_{2} \mathrm{SO}_{4}\right]=0.30 \mathrm{~mol} \mathrm{dm}^{-3}$. 
a standard model for the ferroin-catalyzed BZ reaction [30], which we already used to simulate the BZ/SDS system [20].

Generally, reactions (E1) and (E2) are not included in the ferroin-catalyzed BZ models. Recently $[9,10]$, their contribution has been successfully integrated with the oregonator model $[31,32]$ to emphasize the role of the bromide ions as bifurcation and control parameter. In such a way it was also possible to explain the reduced induction phase before the appearance of waves in the unstirred ferroin-catalyzed systems.

To account for the interaction between the bromine and the surfactant we inserted the equilibrium reaction:

$\mathrm{C}_{14} \mathrm{DMAO}+\mathrm{Br}_{2} \rightleftharpoons \mathrm{C}_{14} \mathrm{DMAO}-\mathrm{Br}_{2}$

we chose the constants for reaction (4) in order to get a ratio between the forward and the reverse constant roughly equal to 2000. A similar value was calculated for the interaction of bromine with the surfactant sodium bis(2-ethylexhyl)sulfosuccinate (AOT) [33].

All constants were taken from the literature (Ref. [14] for reactions (B1)-(B4), Ref. [34] for reactions (E1) and (E2) and Ref. [30] for the rest), except those for the reaction between ferriin and bromomalonic acid which were chosen with an optimization procedure to fit the experimental data. Numerical integration was performed by using CopAsı package [35].

Our simple model is able to reproduce in a qualitative way all the new features induced in the dynamical behavior of the BZ reaction by the presence of the surfactant. Moreover, for a low concentration of $\mathrm{C}_{14} \mathrm{DMAO}$ and/or added $\mathrm{NaBr}$, also a good quantitative accordance between simulations and experimental results was obtained. As an example, we report in Fig. 6 the simulation relative to the progressive addition of $\mathrm{NaBr}$ in solution, when $\left[\mathrm{C}_{14} \mathrm{DMAO}\right]=$ $5.0 \times 10^{-3} \mathrm{~mol} \mathrm{dm}^{-3}$. The threshold value at which the induction period disappears is significantly lower in simulations respect to the experimental value $\left(1.1 \times 10^{-3} \mathrm{~mol} \mathrm{dm}^{-3}\right.$ versus $4.0 \times 10^{-3}$ mol dm${ }^{-3}$ ), nevertheless al low $\mathrm{NaBr}$ concentrations, a good agreement between the two trends was found.

Two aspects should be taken into account to explain the discrepancies between experiments and simulations: (i) In our experimental condition the amino-oxide head group of the surfactant is protonated, therefore the micelles have mainly a cationic character. In these conditions, reactions between anionic species can be significantly influenced. For example, reaction 3 was found to respond in a nontrivial way in the presence of a zwitterionic [36]

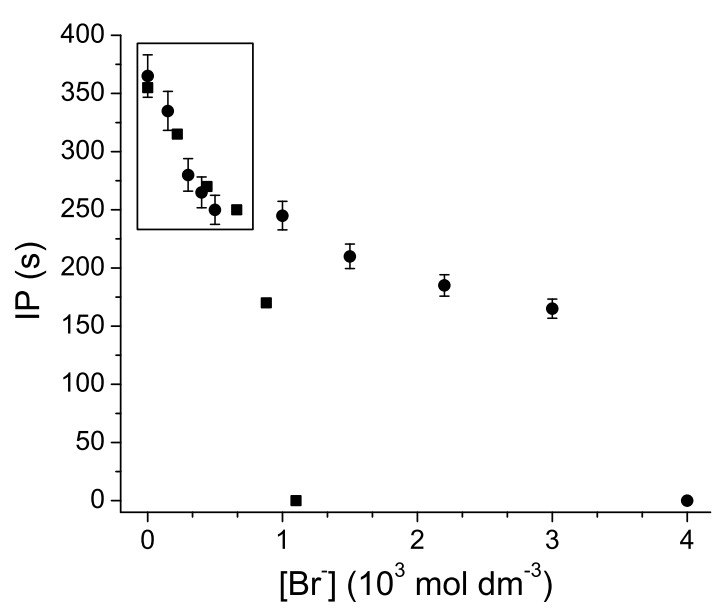

Fig. 6. Comparison between $(\boldsymbol{\square})$ simulations and $(\bullet)$ experimental data relative to the progressive addition of $\mathrm{NaBr}$ to the $\mathrm{BZ}$ mixture at a fixed surfactant concentration $\left(5.0 \times 10 \mathrm{~mol} \mathrm{dm}^{-3}\right)$. When $[\mathrm{NaBr}]<1.0 \times 10^{-3} \mathrm{~mol} \mathrm{dm}^{-3}$ (area inside the rectangle), a good accordance between simulated and experimental results was found. or a cationic [37] micellar system. (ii) $\mathrm{C}_{14} \mathrm{DMAO}$ micelles are known for their ability to change shape depending on the surfactant concentration [26], thus influencing the hydrophobicity of the system. This aspect can also contribute to explain the threshold-like dependence of the IP upon the surfactant concentration.

\section{Concluding remarks}

In this Letter, we showed how in the dynamics of the ferroincatalyzed Belousov-Zhabotinsy oscillating system, new features appear upon the addition of increasing amount of the zwitterionic surfactant $\mathrm{C}_{14} \mathrm{DMAO}$, in stirred closed reactors. In particular, an induction period similar to the pre-oscillatory stage typically manifested by the cerium-catalyzed reaction, was detected. The IP was also found to manifest a threshold-like dependence on the surfactant concentration. The observed trends have been ascribed to the segregation ability typical of the amphiphilic self-assembling systems, which we demonstrated to strongly interact with brominated species. Simulations showed that simply taking into account the interaction of $\mathrm{Br}_{2}$ with $\mathrm{C}_{14} \mathrm{DMAO}$, it is possible to qualitatively reproduce the observed features. Further structural and kinetic studies are in progress to improve the accordance between the experiments and the model.

\section{Acknowledgements}

The authors thank the Università degli Studi di Palermo for financial support (Research Funds ex quota 60\%). Thanks are due to Casimiro Caruso (University of Palermo) for experimental help. The gift of $\mathrm{C}_{14}$ DMAO by Prof. H. Hoffmann (University of Bayreuth) is gratefully acknowledged. We are in debt with anonymous referees for helping us to improve the quality of our Letter with their precious suggestions.

\section{References}

[1] B.P. Belousov, A periodic reaction and its mechanism, in: Sbornik Referatov po Radiatsonno Meditsine, Medgiz, Moscow, 1958, p. 145

[2] J.J. Tyson, Front. Math. Biol. 100 (1994) 569.

[3] I.R. Epstein, J.A. Pojman, An Introduction to Nonlinear Chemical Dynamics: Oscillations, Waves, Patterns, and Chaos, Oxford University Press, New York, 1998.

[4] J.D. Murray, Mathematical Biology, Springer-Verlag, Berlin, 2002.

[5] A.F. Taylor, Prog. React. Kinet. Mech. 27 (4) (2002) 247.

[6] M.-L. Smoes, J. Chem. Phys. 71 (11) (1979) 4669.

[7] N. Ganapathisubramanian, R.M. Noyes, J. Phys. Chem. 86 (26) (1982) 5158

[8] J. Wang, J. Zhao, Y. Chen, Q. Gao, Y. Wang, J. Phys. Chem. A 109 (7) (2005) 1374.

[9] S.G. Sobel, H.M. Hastings, R.J. Field, J. Phys. Chem. A 110 (1) (2006) 5.

[10] H.M. Hastings et al., J. Phys. Chem. A 112 (21) (2008) 4715.

[11] L. Gyorgyi, T. Turanyi, R.J. Field, J. Phys. Chem. 94 (18) (1990) 7162

[12] A. Cadena, N. Perez, J.S. Agreda, D. Barragan, J. Braz. Chem. Soc. 16 (2) (2005) 214.

[13] L. Hegedus, H.-D. Forsterling, L. Onel, M. Wittmann, Z. Noszticzius, J. Phys. Chem. A 110 (47) (2006) 12839.

[14] S. Keki, I. Magyar, M.T. Beck, V. Gaspar, J. Phys. Chem. 96 (4) (1992) 1725

[15] M. Maritato, J. Nikles, L.S. Romsted, M. Tramontin, J. Phys. Chem. 89 (8) (1985) 1341.

[16] F. Cavasino, R. Cervellati, R. Lombardo, M.T. Liveri, J. Phys. Chem. B 103 (21) (1999) 4285.

[17] M. Rustici, R. Lombardo, M. Mangone, C. Sbriziolo, V. Zambrano, M.L.T. Liveri, Faraday Discuss. 120 (2001) 39.

[18] A. Paul, J. Phys. Chem. B 109 (19) (2005) 9639.

[19] L. Sciascia, R. Lombardo, M.L.T. Liveri, J. Phys. Chem. B 111 (6) (2007) 1354.

[20] F. Rossi, R. Lombardo, L. Sciascia, C. Sbriziolo, M.L.T. Liveri, J. Phys. Chem. B 112 (2008) 7244.

[21] V.K. Vanag, I.R. Epstein, Phys. Rev. Lett. 87 (22) (2001) 228301.

[22] V.K. Vanag, Phys. Usp. 47 (9) (2004) 923.

[23] V.K. Vanag, I.R. Epstein, Patterns of nanodroplets: the Belousov-ZhabotinskyAerosol Ot-Microemulsion system, in: K. Al-Shamery, J. Parisi (Eds.), SelfOrganized Morphology in Nanostructured Materials, Springer Series in Materials Science, Berlin, 2008, p. 89.

[24] J.H. Fendler, Membrane Mimetic Chemistry, John Wiley \& Sons Inc., New York, 1983.

[25] J.H. Fendler, Annu. Rev. Phys. Chem. 35 (1984) 135.

[26] H. Hoffmann, G. Oetter, B. Schwandner, Prog. Colloid Polym. Sci. 73 (1987) 95. 
[27] S. Ikeda, M.-A. Tsunoda, H. Maeda, J. Colloid Interface Sci. 70 (3) (1979) 448.

[28] D. Edelson, V.M. Thomas, J. Phys. Chem. 85 (11) (1981) 1555.

[29] R.J. Field, E. Koros, R.M. Noyes, J. Am. Chem. Soc. 94 (25) (1972) 8649.

[30] O. Benini, R. Cervellati, P. Fetto, Int. J. Chem. Kinet. 30 (4) (1998) 291.

[31] R.J. Field, R.M. Noyes, J. Chem. Phys. 60 (5) (1974) 1877.

[32] J.J. Tyson, J. Phys. Chem. 86 (15) (1982) 3006.

[33] L. Garcia-Rio, J. Mejuto, R. Ciri, I. Blagoeva, J.R. Leis, M.-F. Ruasse, J. Phys. Chem. B $103(24)(1999) 4997$.
[34] Y.C. Chou, H.P. Lin, S.S. Sun, J.J. Jwo, J. Phys. Chem. 97 (32) (1993) 8450.

[35] Copasi homepage, URL: <http://www.copasi.org/tiki-index.php?page=homepage>

[36] A. Rodriguez, M.D.M. Graciani, M. Munoz, M.L. Moya, Int. J. Chem. Kinet. 32 (6) (2000) 388.

[37] A. Dominguez, E. Iglesias, Langmuir 14 (10) (1998) 2677. 